\title{
Research advance in failure risk and local strength failure for high arch dams
}

\author{
REN QingWen*, LI Qiang \& LIU Shuang \\ College of Mechanics and Material, Hohai University, Nanjing 210098, China
}

Received September 15, 2012; accepted October 29, 2012

To develop national economy and use the water resources and hydropower resources sufficiently, a lot of high arch dams, with the height of more than $200 \mathrm{~m}$, have been and will be built in China. Although arch dams have good mechanical behavior, there is still failure possibility due to the huge water pressure and high stress level in dam, complex topographic and geologic conditions, formidable environment and high intensity earthquake. As one of the three main aspects concerning the safety of high arch dam, the study on global destruction, has been elaborated in the literatures, and research advance in the other two aspects, namely the failure risk and local damage of high arch dams, will be reviewed in this paper. In recent years, the failure risk of high arch dams has been investigated, and the model for identifying dam failure risk factors has been established. It is shown that the foundation deterioration and strong earthquake are the major risk sources for high dam failure. With the fault tree method, the failure mode and failure probability of high arch dams are studied, and the principle for determining failure mode and the method of calculating failure probability are proposed. Meanwhile, the determination principle of acceptable risk standard for high arch dam was proposed, and the acceptable risk rate and the acceptable standard value of various risk losses were given. For the local damage of arch dam, it is pointed out that the local damage belongs to the strength failure at material level. The study on local failure mechanism of arch dam is reviewed, based on the theories that from traditional strength theory to damage mechanics and meso-mechanics theory. Aiming at the cracking, the main pattern of local failure of high concrete dam, the research advances in the analysis methods and cracking criteria for smeared crack model and discrete crack model are summarized, and the research findings of preventive measures for local failure are shown.

high arch dam, failure risk, local damage, research advance

Citation: Ren Q W, Li Q, Liu S. Research advance in failure risk and local strength failure for high arch dams. Chin Sci Bull, 2012, 57: 4672-4682, doi: $10.1007 / \mathrm{s} 11434-012-5563-7$

To develop national economy, to save energy and to reduce emission, exploitation and utilization of water resources and hydropower resources are continued in China. At present, the height of arch dams under construction and to be built are of $300 \mathrm{~m}$ high level, such as Jinping arch dam $(305 \mathrm{~m}$ high), Xiaowan arch dam (294.5 $\mathrm{m}$ high), Xiluodu arch dam (285.5 m high), and Baihetan arch dam (289 $\mathrm{m}$ high). The construction scale and difficulty of these dams are beyond the current design specifications, and there is hardly successful precedential reference. Moreover most of these high arch dams are located in the western region of China, where

*Corresponding author (email: renqw@ @hu.edu.cn) the topographic and geologic conditions are quite complex, with harsh environment and high seismic intensity as well as frequent geological disasters. In addition the resistance of dam and foundation may be reduced due to the construction quality and environment change. All of these have seriously threatened the safety of high arch dams. Once a high dam fails, catastrophic tragedy would happen and lives would be lost. Therefore, the failure and safety of high arch dam have become a public safety issue. Since the 1980s, the researchers and engineers in China have carried out in-depth research systemically and obtained a large number of innovative results for the high arch dam construction. The level of the results is in the leading position all over the world. 


\section{High arch dam failure modes and failure risk}

Arch dam is a high order statically indeterminate three-dimensional structure, which has good mechanical properties, great overload capacity and high safety. But due to huge loads, high stress levels, complex topographic and geologic conditions, harsh environment and high seismic intensity, some operating arch dams still fail. In December 1959, Malpasset arch dam in France suddenly broken, which killed more than 500 people and caused property losses amounting to 30 billion francs, and the important reason was the low shear strength of the left bank skewback caused by the poor rock mass quality, cranny development and containing mud. Before the accident, heavy rain had continued for 29 days, with rainfall up to $490 \mathrm{~mm}$, which led to further deterioration of the dam foundation rock mass. The Pacoima arch dam in U.S. suffered earthquakes with magnitude 6.6 twice in 1971 and 1994, although the dam itself was not significantly damaged, the joint between left dam abutment and thrust block was opened. After the joint was opened for about $6.4-9.7 \mathrm{~mm}$ in the first earthquakes, 35 prestressed anchors of $3087 \mathrm{kN}$ were used for reinforcing. After the second earthquake, the joint was opened for another $47 \mathrm{~mm}$, and parts of the prestressed anchors were ruptured. On October 9 1963, a landslide took place in the upstream reservoir bank of Italy Vaiont arch dam, whose height is $262 \mathrm{~m}$, a 300 million cubic meters of rock mass glide into the reservoir at high speed, and 50 million cubic meters of water was extruded, which destroyed a city and several towns, and the underground powerhouse was destroyed by the air shock wave. About 3000 people died in the accident.

At present, dam safety evaluation is mostly based on the specification method [1,2] and modern numerical method, such as finite element method [3-6]. These methods are conducted with specified failure approach, and the probability of failure is not involved as well as the research on failure mode, which results in a lot of artificiality in analysis. In addition, the allowable safety degree and the potential losses are not combined so that the balance between safety and economy cannot be considered, and the safety of structure is checked only from the technical perspective $[7,8]$.

Risk analysis is to study the system risk when it completes its intended function under certain conditions, including system accident probability and consequence determination. For risk analysis, the safety evaluation has to analyze the risk source, failure mode and failure probability, and to estimate the risk of loss. At present, risk analysis of water conservancy is focused on the hydrological risk and hydraulic risk, but there is hardly risk analysis for the structural aspects. The only relevant literatures [9-11] are mainly on the issues of overtopping and instability failure of embankment dam, since the structure and failure mechanism are relatively simple. Risk analysis for concrete dam especially the high arch dam is just in the infancy stage, and its main research results are as follows.

(i) Identification of risk sources. It is shown that the major factors of high concrete dam failure can be divided into internal and external, based on the on-site investigation and data statistical analysis of high concrete dam accidents both at home and abroad. The external factors are the earthquake and subsequent secondary disasters, floods, explosions, which increase the effect on the dam. The internal factors are the unfavorable geological structure in dam foundation, damages and defects in dam body, and material and structural deterioration caused by the long term performance as well as change of environmental conditions, all of which would reduce the bearing capacity of the dam. It can be drawn from both of the measured data and the research of dam failure risk factors $[12,13]$ that flood is the major cause for the embankment dam to break, and there are many achievements about flood risk analysis [14-16]. While the major reasons for high arch dam failure are the foundation deterioration and strong earthquake [17], the related results are lack. Gu and Wang [18] established the dam risk identification ANP model and the dam risk network structure model, by which the priority order of dam failure risk factors can be obtained, and the main risk factors of dam breach can be determined. The ANP model is just suitable for earth rockfill dam, and it is difficult for concrete dam.

(ii) Failure modes and failure probability of high arch dam. According to [19], the possible failure modes of high arch dam can be summarized as: (1) The strength failure of the dam body; (2) buckling of the dam body; (3) destabilization of arch dam along its base surface; (4) slip of the dam abutment rock; (5) global destruction of arch dam and foundation system. The consequence of failure is that the arch dam cannot be in normal operation or lose the carrying capacity. Different failure modes have different failure probabilities, and the specified failure mode is not necessarily the most possible failure mode. In order to find the maximum probability failure mode, Chen and Ren used the fault tree method to study the failure mode and failure probability of high arch dam, under the effect of some kind of risk source, and proposed the principle for determining high arch dam failure mode [20-22] and the calculation method of failure probability [23,24]. However, it is difficult to calculate the failure probability when applying the method because of very few samples of concrete dam break. Jin et al. [25] proposed the improvement of SVM response surface reconstruction method, and combined it with the FORM method and the importance sampling method in reliability analysis; the exact solution of failure probability for some simple structures can be obtained. It is hard to apply the method to dam.

(iii) The research of dam failure risk and acceptable risk. In addition to determining the failure probability, the risk analysis of high arch dam safety is also needed to study the failure loss, including economic loss, life loss, environment and ecology loss and social impact. Because the loss of dam 
breach risk is fuzzy and the suffered loss area is vast, Gu [26] proposed the fuzzy comprehensive evaluation method and established a fuzzy comprehensive evaluation index system, through which the level of various losses can be determined. Based on the fuzzy matter-element and exponential smoothing algorithm, Wang et al. [27,28] proposed the evaluation method of life loss caused by dam breach and the evaluation method of loss caused by dam breach based on GIS. But the exact risk loss is hardly obtained since it is difficult to calculate quantitatively the environment and ecology loss as well as the social impact.

In order to make the correct safety warning of dam breach, the acceptable risk standard [29] needs to be determined, for which many aspects should be considered comprehensively, such as the characteristics of system, science and technology level, economic development, the value of human life and its recognition degree, as well as the harm scope and degree and other factors. Gu [30] established the comprehensive risk standard determination method based on F-N curved surface, and the acceptable comprehensive risk standard value was given. Chen [31,32] presented the principle of determining high arch dam acceptable risk standard, and the acceptable risk rate as well as the acceptable standard value of various risk losses.

\section{High arch dam failure process, mechanism and analysis methods}

Existing research [33] shows that the buckling failure of arch dam would generally not happen unless the high strength material is used and the arch ring is very thin. Both numerical simulation and geomechanical model test [34-36] show that since arch dam is a hyperstatic three-dimensional structure, the dam failure generally starts from local damage and cracking, and the area of damage and cracking gradually grows with loading increase or bearing capacity degradation, eventually ends in global destabilization. This is a progressive failure process from local damage to global destruction. Figure 1 shows the growing process of cracking and yield area of Xiaowan high arch dam as the upstream water pressure increases [37]. Some cases of arch dam destruction also illustrate the failure process [12].

It can be concluded that there are two levels in a high arch dam failure: the local damage at material level and the global destruction at structure level. The former is the local cracking, crushing or other damage forms, and the latter represents the loss of carrying capacity. Apparently, they are different, but have some connection. If only the local damage at the material level happens, the dam still has a certain bearing capacity, and can continue service. Only if the damage area expands to a certain extent and the bearing capacity is lost, will the global destruction of the dam occur. The failure mode may be the slip of the abutment rock, or the destabilization of arch dam along its base surface or the global destruction of dam and foundation.

Obviously, the local damage is caused by lack of material strength and it belongs to the strength failure. Whether damaging or not, it can be determined by examining the stress and strength. Although the global destruction of arch dams is called "stability" by almost all the researches, and a lot of analysis methods are developed [4,38-40], they are still in the frame of strength failure in essence, and analysis on global destruction is still based on the strength theory. Ren pointed out that the global failure of arch dam is a stability problem and it is the extreme point destabilization according to the character that the load-displacement curve obtained in failure process possesses an extreme point. Hence the global destruction of arch dam is a physical instability which starts from strength failure, and the instability is due to the nonlinearity existing in the relation of stress and strain. Therefore, the global destruction analysis of high arch dam should be based on the stability theory of mechanical system, and the corresponding analytical method and failure criterion can be obtained through establishing and solving the physical disturbance equation. This has been elaborated in several articles of Ren [35,37,41] and would not be discussed here. The key point will be focused on the local damage of high arch dam.

\section{Local damage of high arch dam}

High arch dams are made up of concrete, rock and the rock joints, which are mostly brittle materials with low or no tensile strength. Different from middle and low-height arch dams, both the tensile stress and the compression stress are considerable large in high arch dam, so it is more likely to be damaged under loading. This is not allowable in the current design codes. Many researches have been done on this issue. In what follows, the research advance will be stated in three aspects respectively, namely the local damage mechanism, the analysis methods with corresponding criterion, and some prevention measures.

\subsection{The damage mechanism of dam concrete and foundation rock}

Cracking, shear and compression failures are the common patterns in dam concrete and foundation rock. These failures are part of strength failure at material level, and they are mostly caused by excessive stress values. The failure mechanism has been studied from different perspectives with various theories and methods.

(i) Study on local damage based on traditional strength theory. In the context of traditional strength theory, material is considered to be failed if the maximum principle stress exceeds the material strength. This is a uniaxial strength theory. But the reality and experiments show that the actual strength is different from the uniaxial strength 
(a)

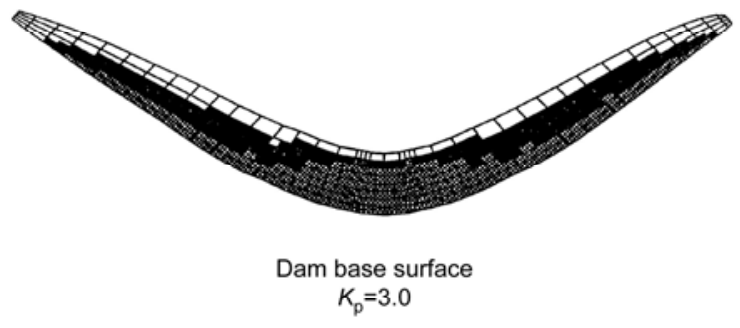

(b)

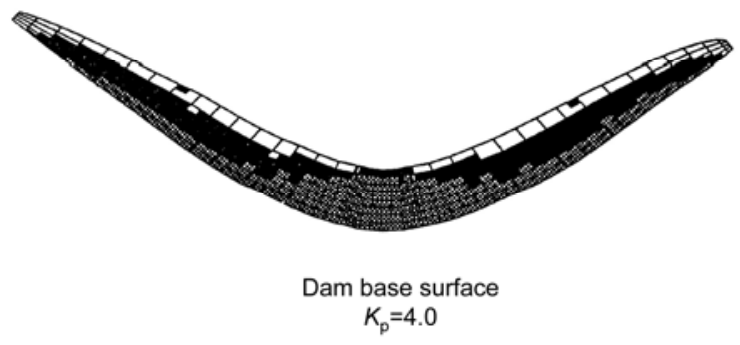

(c)



Fissure zone
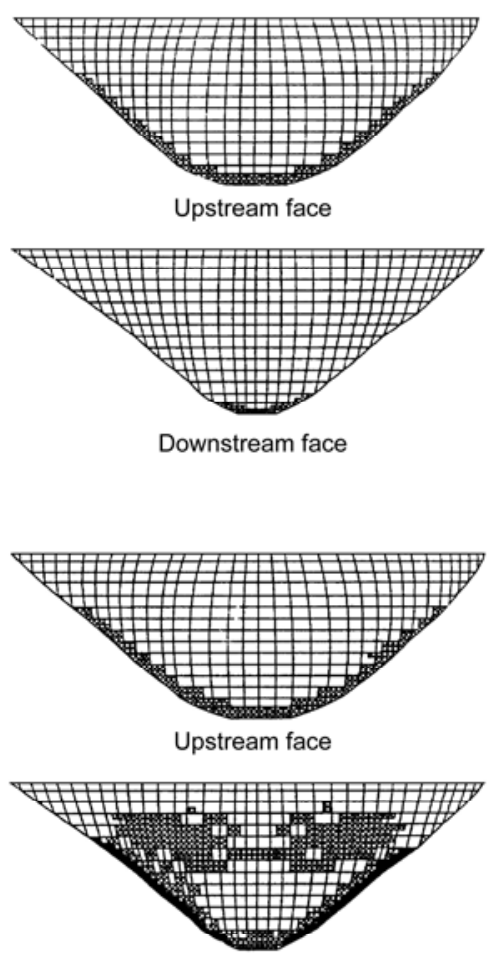

Downstream face

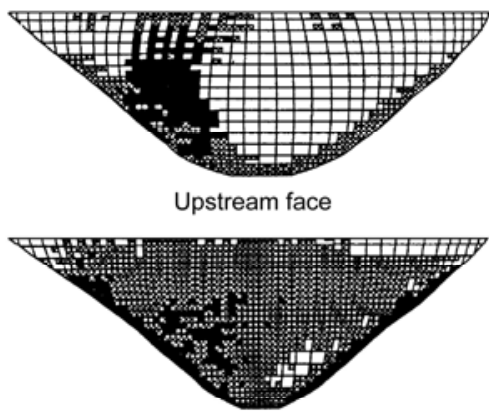

Downstream face

Figure 1 Destruction region in upstream, downstream and base surfaces of Xiaowan arch dam.

and there are multiple failure patterns when the material is in a complex stress state. This implies that the traditional uniaxial strength theory is not consummate and the multi-axial theory should be adopted. Based on a lot of experiment data and solid mechanics theory, some models are established to reflect the complex material mechanics behavior, such as dilatancy and different behavior in tension and compression, by considering the influence of principle and deviatonic stresses. For concrete, there are Ottosen model, and Chen-Chen model [42-45] as well as the model proposed by Guo and Wang [46]. For rock like material, it is more sensitive to the stress state, and the commonly used model, such as the Mohr-Coulomb model and D-P model, are hardly able to take into account the influence of stress state on failure. In order to reveal the failure mechanism, the quasi triaxial and true triaxial experiments have been used to investigate the change of strength and frictional angle under different confining pressures, and some complex multi-axial strength models have been presented [47-49]. Xiao et al. [50,51] investigated the existing constitutive models and proposed a unified constitutive model for both isotropy and anisotropy conditions, and applied it to the analysis of granular soil.

Besides the stress criterion, the strain criterion is also used in the failure mechanism researches of concrete and rock [52]. In addition, energy, which can reflect both stress and strain at the same time, has the advantage of global representation and is better for revealing the failure of ma- 
terial. Xie et al. [53] studied the damage of rock with the energy method, and the energy variation tendency in the local failure process.

(ii) Study on local damage based on damage mechanics theory. Damage mechanics as a newly branch of solid mechanics was developed during the 1960s. With either a continuous damage scalar variable or damage field variable, some subtle defects in material are reflected, and then the evolutionary process and the effects of the defects on the material mechanical behavior under loading can be studied [54,55]. Both concrete and rock are heterogeneous material essentially, in which there are a lot of defects and micro-cracks. With damage variables representing the defects, the failure of dam concrete and foundation rock can be studied more realistically.

With damage mechanics theory, Gunn [56] studied the safety degree of arch dam, and Duan et al. [57] did some research on the failure mechanism of rock excavated relaxation and its influence on the performance of Jinping arch dam. The results showed that the relaxation of foundation following excavation has a negative impact on the performance of the arch dam in general, which would lead to an increase in dam stress in local areas near the relaxation zone. The research disclosed that the decrease extent of elastic modulus in the relaxation zone is the main factor affecting stresses in the dam. Using an anisotropic damage model, Du et al. [58] studied the failure of Dagangshan arch dam under strong earthquake. They pointed out that in the dynamic analysis of arch dam, both of the anisotropic property and the asymmetry characteristic of tension and compression should be taken into account in the damage constitutive model, and the failure of dam is mainly caused by the tension fracture. On the basis of it the dynamic safety of the dam was evaluated. In [59-62], by treating the existing defects or cracks in dam as the structural damage variable, the evolution of these defects and the effects on dam safety were studied. In addition, Lu et al. [63] and Deng et al. [64] also studied the failure of concrete dam under multi-field coupling situation, like seepage-stress coupling and temperature-stress coupling, with the damage mechanics theory. The damage mechanics theory can reveal the fracture and failure mechanism in some extent, but either isotropic or anisotropic damage model treats the material as homogeneous, with which the shape and size of crack in concrete can not be analyzed.

(iii) Study on local damage based on meso-mechanics theory. Both concrete and rock are essentially heterogeneous material. Concrete is a material made up of aggregate, cement mortar and the interface between them. Rock mass is also heterogeneous because of containing some interfaces like joints and fractures, even if the intact rock is made up of types of mineral crystals. Although these ingredients are quite small in size, they affect the material mechanical properties a lot. Since the traditional solid mechanics theory can hardly handle heterogeneous problem, the meso-mechanics theory, a newly established branch of solid mechanics theory, was proposed to analyze the failure mechanism of heterogeneous materials. Using the meso-mechanics theory, the mechanical property and behavior of heterogeneous material can be studied, the initiation and propagation of damage be simulated, and the failure mechanism can be revealed.

Concrete cracking has always been a hot-spot in dam engineering, but the crack initiation and propagation mechanism are still not well understood. With the development of computer and based on the theory of meso-mechanics, some outstanding researchers as Wrigers [65], Cusatis [66], Bazant [67,68] and Leite [69] established several models to study the problem with meso-mechanics theory and uniformization method. The results well disclosed that the initiation of crack is mostly from the interface between the aggregate and mortar, and the aggregate shape and grading as well as cement mortar strength affect a lot on the concrete strength. Du et al. [70] established a numerical concrete model for simulating aggregate with arbitrary shape (Figure 2). Using this model the initiation and propagation of cracks were studied (Figure 3), and the load-displacement curve was obtained, which is quite consistent with the laboratory experiment (Figure 4). Nazari and Riahi [71], Zhu et al. [72,73] and Xu et al. [74] studied the influence of inclusion and imperfect interface on the material macroscopic behavior, which explains the brittle fracture and shear dilatancy of concrete better, and plays a positive role in research of concrete local damage. Mungule [75] and Grassl [76] explored the microscopic structure of concrete containing the interfaces between aggregate and mortar, and presented the influence on the macroscopic property and the fracture process zone (FPZ). In [77], with meso-mechanics method, $\mathrm{Wu}$ analyzed the cracking process from microcrack initiation to macroscopic fracture in concrete dam, and evaluated the effect of different location and depth of crack on the dam safety, which were compared with lab model tests.

Both theoretical results and engineering practice have shown that the behavior of foundation rock is greatly affected by structure planes inside the rock. Traditionally, the Mohr-Coulomb criterion is used for failure analysis of the plane, namely shear failure along the plane will happen as the shear stress exceeds the shear strength. The macroscopic mechanical parameters in Mohr-Coulomb criterion, namely the cohesive strength and the frictional angle, are from laboratory tests. According to meso-mechanics it has been revealed that failure of structure plane is affected not only by the mechanical property of filling in plane but also by the geometry, microscopic structure as well as the filling percentage [78,79]. Dui et al. [80-83] developed the basic theory of meso-mechanics. They obtained an explicit theoretical solution of Eshelby tensor for transversely isotropic inclusion; and proposed the meso-mechanics model of multiple medium for analyzing fractured layer rock; established 


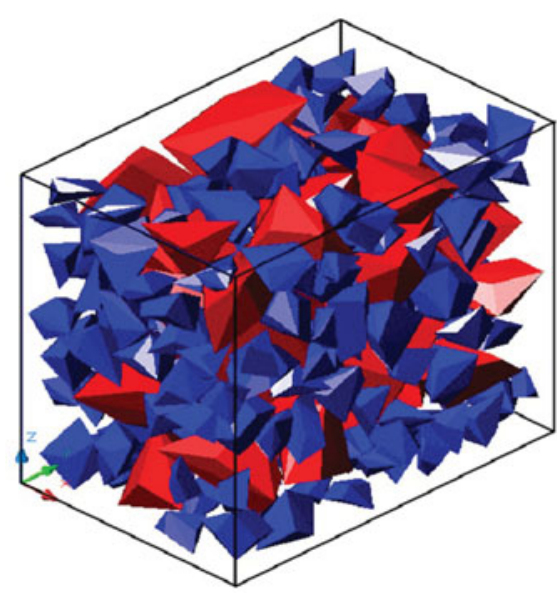

Figure 2 3D random concrete aggregate model.

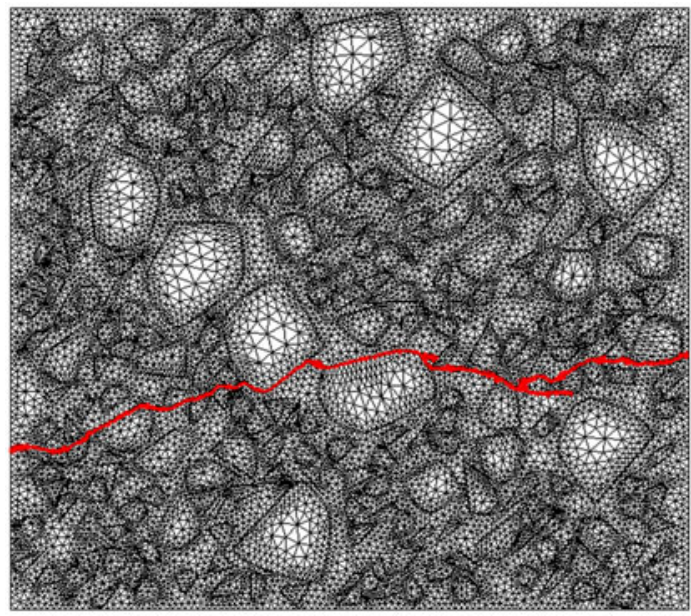

Figure 3 Numerical simulation of concrete cracking.

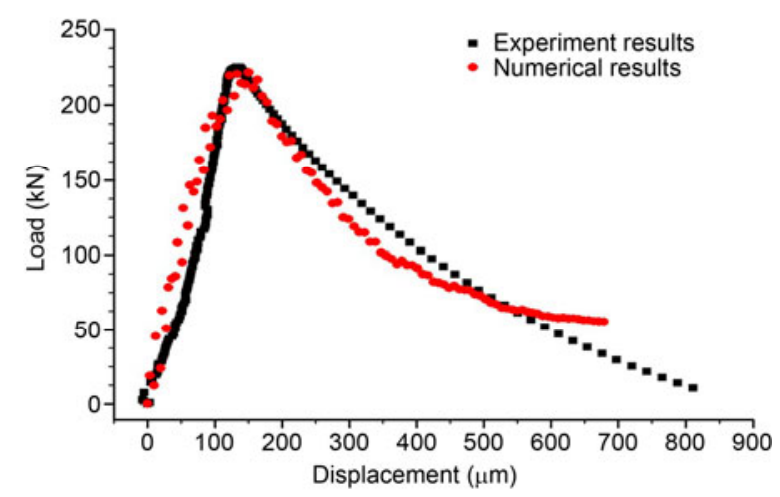

Figure 4 Load-displacement of Jingpin arch dam concrete.

several non-linear constitutive models (Figure 5) for structure plane, which can reflect the post-peak softening due to wear of ledges on the plane, the coupling in normal and tangential directions, and the effect of the filling material.

(iv) Local damage and failure research under coupling condition. Temperature variation and seepage are the two
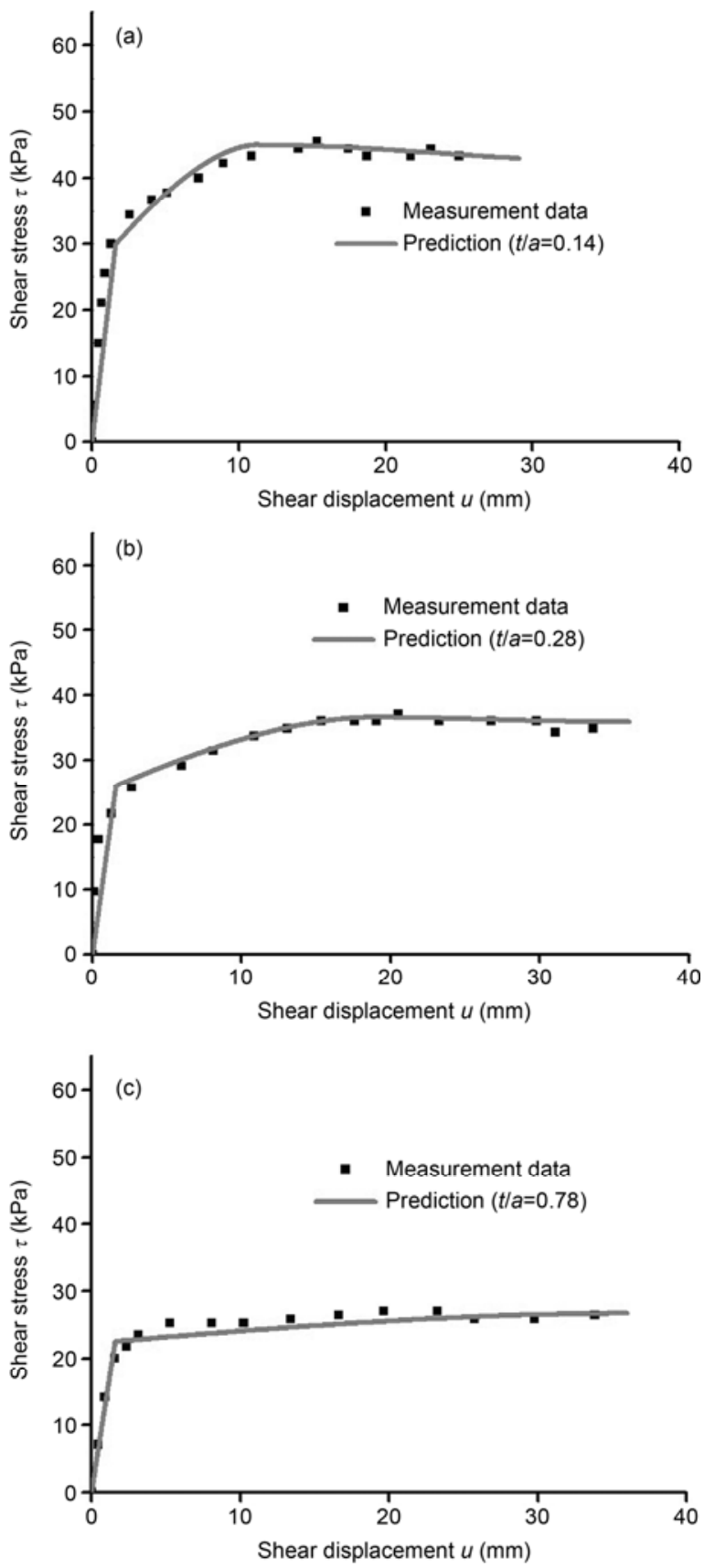

Figure 5 Shear stress-displacement curves with different filling percentages.

mainly factors for local failure of arch dam. After reservoir raised, the existing cracks in dam and the structure planes in foundation rock would become the seepage channels, and the coupling effects of stress-seepage and deterioration of the planes caused by seepage could increase the failure possibility of the arch dam. Chai and $\mathrm{Xu}$ [84] and $\mathrm{Hu}$ et al. [85] pointed out that seepage is unfavorable for dam global stability, especially the sudden change of water level would cause the variation of seepage field in the foundation rock, which is more like to introduce the local damage in rock foundation. Yang et al. [86] and Huang et al. [87] studied 
the seepage-stress coupling with meso-mechanics approach and obtained some meaningful results. In [88-92], some approaches were proposed to handle the temperature-seepagestress coupling problem, and some progresses were obtained both for engineering practice and further research.

\subsection{Safety analysis of local strength failure}

Strength check is one of the most important parts for the safety evaluation of high arch dam. Besides the multiple arch-cantilever method requested by the dam design codes, many modern numerical methods and tests are developed to obtain more realistic stresses and displacements for static [93-98] and dynamic [99-104] analysis of dam. With these methods and tests, the location and area as well as the extent of cracking, crushing and shear failure can be figured out. Since cracking is the major form of local strength failure for high arch dam, it is becoming more and more important in the content of high arch dam safety evaluation. Currently, there are mainly two kinds of cracking models: smeared crack model and discrete crack model.

(i) Smeared crack model for cracking analysis. Smeared crack model is the most widely used in concrete cracking analysis, in which, the cracks are treated as a series of parallel micro-cracks in the element, and the stiffness deterioration in normal direction of the micro-cracks is used to represent initiation and propagation of the micro-cracks [105].

In engineering practice, finite element method (FEM) is commonly adopted for calculating the maximum principle tensile stress in arch dam and compares the results with the tensile strength of concrete. It is considered that cracking would happen if the calculated maximum principle tensile stress exceeds the tensile strength, and the propagation direction of crack is normal to the maximum principle tensile stress [106,107]. Bazant [108,109] had contributed a lot to the establishment and development of the smeared crack model. He explored the scaling law of FEM mesh and the fracture energy, and presented a method for determining the fracture energy parameter independent from mesh and the optimal mesh size for computing. At present, the smeared crack model has been widely used in the analysis of crack initiation [110], crack stability induced by temperature [60] and crack expansion in long-term operation [59]. In almost all the popular commercial software, such as ABAQUS, ANSYS, and MARC, there is a special module of the smeared crack model.

The recently developed peri-dynamics theory is also capable of analyzing material failures. Huang et al. [111] applied the PD method to failure process analysis of concrete, which can display initiation and propagation of the crack dynamically. But there is still a long way to go to apply it to $3 \mathrm{D}$ analysis and actual engineering.

The shortcoming of smeared crack model is that it only gives a certain range of cracking by elements, while the shape and location of the crack can not be obtained. The discrete crack model could handle the problems.

(ii) Discrete crack model for cracking analysis. Discrete crack model is usually adopted in fracture mechanics method for analyzing initiation and expansion of concrete crack [112-114].

Kaplan [115] first applied the classical fracture mechanics to concrete fracture research in 1961. Since then, a lot of achievements have been made on concrete fracture with fracture mechanics. In 1976, Hillerborg et al. [116] proposed a model called fictitious crack model (FCM) for simulating the cohesive behavior in the fracture process zone (FPZ) in concrete, and the corresponding parameter determination method were also given. The model is based on the fracture mechanics theory and it considers the existing FPZ in the crack tip of concrete, so it could treat the cracking problem more realistically, and is widely welcomed by the researchers. But for this model it is difficult to remesh as the crack propagates. There are usually two ways to overcome the problem. One is by assuming the crack location and direction a prior [117], which, however, is usually not in consistent with realistic situations; the other way is to remesh during each step in the expanding process of the crack [118], which is quite costly in computing time.

Extend finite element method (XFEM) proposed by Belytschko et al. [119,120] can avoid the contradiction between FEM mesh and crack expansion. The method is based on the partition of unity theory proposed by Babuska and Melenk [121] in 1996. By introducing the Heaviside function and the asymptotic displacement fields near the crack tip into the standard FEM shape function, the discontinuous due to crack can be handled with ordinary mesh, and in this way the crack initiation and expansion can be simulated independently of the FEM mesh. Ren et al. [122-127] applied the XFEM approach to the analysis of concrete cracking and hydraulic fracturing, and presented the crack expanding path in dam under loading and the effect of cracks on the dam safety. XFEM is an effective method to analyze crack problem, but the calculation efficiency and programming generalization still need to be studied in the coming years.

Both of the smeared crack model and the discrete crack model have advantages and shortcomings, so the idea of combing the two approaches for concrete cracking will have a promising future [128].

(iii) Crack criterion of concrete. Due to a lot of factors affecting concrete cracking, the different structural performance requirements and working conditions, the definition of cracking is quite different and there are several crack criteria. Generally, the concrete crack criterion can be concluded into strain criterion and stress criterion.

The maximum strain and stress criterion are the most widely used traditional crack criterion. They assume that fracture would happen if the maximum principle stress exceeds the material strength or the maximum principle strain 
is larger than the allowable value. The criteria are simple and easy to use in practice. The D-P criterion is also a very popular crack criterion used in engineering practice, which can be found in lots of commercial software. But it is also found that the parameter of dilatancy angle $\psi$ has great effects on the cracking area in smeared crack model, and the inconsistency between the dilatancy angle and the frictional angle could cause convergence difficulty.

Due to a lot of unpredictable factors, cracking of concrete dam can hardly be avoided, and there are many cracked dams that are still of good operation. Therefore Ren [129] proposed the idea of allowable cracking in the concrete dam, i.e. cracking in dam concrete is allowed, but the crack should be controlled within a certain width and depth. With the experimental data of concrete under tension, the relations between the tensile strain, crack width and the permeability coefficient were set up, and a cracking criterion based strain was established based on seepage prevention [110]. Because the data of pulling crack of concrete samples are from the foreign literatures $[130,131]$, not from the tests of dam concrete in China, there is a long way to apply it to dams.

In the context of fracture mechanics, the crack initiation and expansion can be figured out according to the stress intensity factor and the fracture energy. Based on a lot of experimental data, Xu et al. [132,133] proposed the double $\mathrm{K}$ criterion for concrete crack, and presented the relation between the G-R curve of crack expansion and the material softening regime. The obtained results have been used for restricting crack of both concrete dam and concrete pressure tunnel. Bao et al. [134] obtained the energy distribution near the crack tip when crack expanding by using the comentropy analysis.

There are many local damage criteria at present, but due to the complexity of failure mechanism, the criteria are just a guide in practice. For the heterogeneous material like concrete, the combination of fracture mechanics and meso-mechanics would be a possible approach to analyze the evolution process from micro-crack initiation, nucleation to macro-crack formation, which can be called the multi-scale approach. But a lot of work is needed to be done to achieve the goal.

\subsection{Preventive measures of local damage}

Many factors would cause local damage in high arch dam $[61,63,135,136]$, especially cracking. From dam shape design, foundation excavation and reinforcement, concrete pouring and temperature control to loading action, all of these affect the cracking of concrete. A lot of work has been done on cracking prevention and control by engineers and researchers.

The shape design of high arch affects not only the global stability but also the local stress state. It has been proved [137-139] that the optimization of dam shape would reduce the high stress area in dam body and decrease the maximum value of stresses, which could reduce the possibility of dam cracking.

The pouring scheme and the corresponding temperature control are the key measures for cracking prevention. Zhong et al. [140-142] conducted some research on the order of pour by pour and the temperature control scheme of dam concrete to predict the maximum temperature during the pouring process. The obtained achievements have been used in practice.

Crack detection and monitoring are also important issues for safety control of arch dam. Fu et al. [143] studied the possible cracking of Xiaowan high arch dam under temperature-stress coupling action according to the monitoring data, which can provide the scientific basis for cracking prevention. Besides, Bao et al. [144,145] and Gu et al. [146] studied the variation of existing crack in dam and gave some advises for dam safety. And the researches of Liu et al. [147] and Lei et al. [148] on monitoring of crack initiation and expansion were from microscopic and macroscopic views respectively. The problem is that the fine crack can not be detected in present, so it is difficult to verify the above methods.

\section{Conclusions}

Arch dam has a good mechanical behavior, but due to the huge water pressure and high stress level in dam, complex topographic and geologic conditions, formidable environment and high intensity earthquake, there is still a risk of failure. The failure of high arch dam has two levels: the local damage at material level and the global destruction at structure level. Ren had summarized the recent research advances in global safety of high arch dam in [35,37], including the slip of the abutment rock, the destabilization of arch dam along its base surface and the global destruction of high arch dam. The research advance in the local damage and failure risk of high arch dam are focused in this paper, as the supplements for safety research of high arch dam.

The failure risk research of high arch dam was reviewed, and the model used for identifying the dam failure risk factors was presented with the priority order of risk factors. Accordingly, the major risk sources of high dam failure were identified as the foundation deterioration and strong earthquake. Using the fault tree method, the failure mode and failure probability of high arch dams were introduced, and the principle for determining failure mode of high arch dam and the calculation method of failure probability were briefed. Meanwhile, the determination principle of acceptable risk standard for high arch dam was presented, and the acceptable risk rate and the acceptable standard value of various risk loss were given.

It is pointed out that the local damage belongs to strength failure at the material level. The study on the local failure 
mechanism of arch dam is reviewed, based on the theory that is from traditional strength theory to damage mechanics and meso-mechanics theory. Aiming at the cracking, the main pattern of local failure of high arch dams, the research advance in the analysis methods and cracking criteria for smeared crack model and discrete crack model are summarized, and the research findings of preventive measures for local failure are shown.

This work was supported by the National Natural Science Foundation of China (11132003 and 51079045).

1 Committee of Developing and Innovating of PRC. Design specification for concrete arch dam (DL/T 5346-2006). 2006

2 Ministry of Water Conservancy of PRC. Design specification for concrete arch dam (SL 282-2003). 2003

3 Wells G N, Sluys L J. A new method of modeling cohesive cracks using finite elements. Int J Numer Meth Eng, 2001, 50: 2667-2682

4 Bao T F, Xu B S, Zheng X Q. Hybrid method of limit equilibrium and finite element internal force for analysis of arch dam stability against sliding. Sci China Tech Sci, 2011, 54: 793-798

5 Gunn R M. Non-linear design and safety analysis of arch dams using damage mechanics. Int J Hydropower Dams, 2001, 8: 67-74

6 Huang Y, Jin F, Wang G L, et al. Stability and propagation of cracks at the heel of high arch dams. J Tsinghua Univ, 2002, 42: 555-559

7 Jia C, Li Y F, Chen J. Some questions about risk analysis based on reliability in high dam constructing. J Hydraul Eng, 2007, 38: 118-122

8 Hartford D N D, Baecher G B. Risk and Uncertainty in Dam Safety. London: Thomas Telford Ltd, 2004

9 Hokstad P, Steiro T. Overall strategy for risk evaluation and priority setting of risk regulations. Reliab Eng Syst Safe, 2006, 9: 100-111

10 Ma R Y, Huang H Y, Liao X T. Analysis of overflow fuzzy risk on earth dam. J Safe Environ, 2004, 4: 15-18

11 Liu Y, Wang Z Y, Liu G H, et al. Study on quantitative risk assessment method for earth-rock dam failure. Water Power, 2005, 31: 44-47

12 Ru N H, Jiang Z S. Dam Failure and Security Arch Dam. Beijing: China Water Conservancy and Electricity Press, 1995

13 Chen Z T, Ren Q W. Uncertainty factors in high arch dam safety analysis. J Nanjing Univ Sci Tech, 2006, 30: 722-726

14 Diao Y F, Wang B D. Risk analysis of flood control operation mode with forecast information based on a combination of risk sources. Sci China Tech Sci, 2011, 54: 1949-1956

15 Liang Z M, Li B Q, Yu Z B, et al. Application of Bayesian approach to hydrological frequency analysis. Sci China Tech Sci, 2011, 54: 1183-1192

16 Zhang Y P, Wang G L, Peng Y, et al. Risk analysis of dynamic control of reservoir limited water level by considering flood forecast error. Sci China Tech Sci, 2011, 54: 1888-1893

17 Hendron A J, Patton F D. The vajont slide: A geotechnical analysis based on new geologic observations of the failure surface. Eng Geol, 1987, 24: 475-491

18 Gu S P, Wang B. The ANP model for dam risk identification of the hydropower project. In: Asia-Pacific Power and Energy Engineering Conference, APPEEC 2010. 328-330

19 Ren Q W, Qian X D, Zhao Y, et al. Methods for analyzing sliding resistance stability along the base surface of high arch dam. J Hydraul Eng, 2002, 33: 1-7

20 Chen Z T, Ren Q W. Research on high arch dam failure probability based on failure mode. Key Eng Mater, 2007, 349: 597-601

21 Chen Z T. Failure mode and failure probability of high arch dam. J Nanjing Univ Aeron Astron, 2007, 39: 530-534

22 Chen Z T. Risk-based research on failure mode of high-arch concrete dam. Key Eng Mater, 2008, 269: 385-387

23 Chen Z T. Model for failure probability calculation and risk evaluation of high arch dam based on risk management. In: International
Conference on Risk and Reliability Management, 2008. 477-480

24 Chen Z T, Ren Q W. Failure probability calculation of high arch dams with multi-failure modes. Hydrosci Eng, 2007, 2: 54-57

25 Jin W L, Tang C X, Chen J. SVM based on response surface method for structural reliability analysis. Chin J Comput Mech, 2007, 24: $713-718$

26 Gu S P. Integrated risk criteria based on fuzzy comprehensive evaluation of dam failure consequences. In: Chinese Academy of Engineering 2010 Basin Water Security Major Projects Safety High-level Forum, 2010. 412-418

27 Wang Z J, Gu C S, Liu H C. Estimation of loss-of-life caused by dam break based on fuzzy matter-element and exponential smoothing method. J Yangtze River Sci Res Inst, 2009, 26: 25-28

28 Wang Z J, Zhang Z J, Li Z Y. Study on evaluation method of losses caused by dam breach based on GIS. Water Power, 2008, 34: 75-87

29 Vrijling J K, Van Hengel W, Houben R J. Acceptable risk as a basis for design. Reliab Eng Syst Safe, 1998, 59: 141-150

30 Gu S P. F-N curved surface method for establishing the integrated risk criteria of dam failure. Sci China Tech Sci, 2011, 54: 597-602

31 Chen Z T, Ren Q W. Research on standard of acceptable risk for high arch dam in developing countries. Key Eng Mater, 2007, 348: 601-604

32 Chen Z T. Analysis of the existing situations and problems in failure risk evaluation of high arch dams. J Hydroelectr Eng, 2010, 29: 70-75

33 Ren Q W, Wang B L. Discussion on slenderness coefficient of arch dams. J Hohai Univ, 2003, 31: 1-4

34 Chen X, Zhou W Y, Huang Y S. 3D FEM analysis for failure simulation of Jinping arch dam. Chin J Rock Mech Eng, 2002, 21(suppl 2): 2403-2407

35 Ren Q W, Li Q, Jiang Y Z. Theory and methods of global stability analysis for high arch dam. Sci China Tech Sci, 2011, 54(suppl 1): 9-17

36 Zhang L, Fei W P, Li G L, et al. Experimental study on global geomechanical model for stability analysis of high arch dam foundation and abutment. Chin J Rock Mech Eng, 2005, 24: 3465-3469

37 Ren Q W. Theory and methods of high arch dam's entire failure under disaster conditions. Eng Mech, 2011, 28(suppl 2): 85-96

38 Wang D D, Li Z Y, Li L. Three dimensional efficient meshfree simulation of large deformation failure evolution in soil medium. Sci China Tech Sci, 2011, 54: 573-580

39 Yang Q, Cheng Y G, Zhao Y N. Limit analysis method based on nonlinear programming and its application. Eng Mech, 2004, 21: 15-19

40 Ren Q W, Jiang Y Z. Ultimate bearing capacity of concrete dam involved in geometric and material nonlinearity. Sci China Tech Sci, 2011, 54: 509-515

41 Ren Q W, Xu L Y, Wan Y H. Research advance in safety analysis methods for high concrete dam. Sci China Tech Sci, 2007, 50(suppl 1): $62-78$

42 Ottosen N S. A failure criterion for concrete. J Eng Mech Div ASCE, 1977, 103: 527-535

43 Chen A C T, Chen W F. Constitutive relation for concrete. J Eng Mech Div ASCE, 1975, 101: 465-475

44 Kotsovos M D. A mathematic model of the deformation behavior of concrete under generalized stress based on fundamental material properties. Mater Struct, 1980, 13: 289-298

45 Chen W F. Plasticity in Reinforced Concrete. New York: McGraw Hill Book Company, 1982

46 Guo Z H, Wang C Z. Investigation of strength and failure criterion of concrete under multi-axial stresses. Chin Civil Eng J, 1991, 24: 1-13

47 Kulatilake P H S W, Shou G, Huang T H, et al. New peak shear strength criteria for anisotropic rock joints. Int J Rock Mech Mining Sci Geomech, 1995, 32: 673-697

48 Maghous S, Bernaud D, Freard J, et al. Elastoplastic behavior of jointed rock masses as homogenized media and finite element analysis. Int J Rock Mech Mining Sci, 2008, 45: 1273-1286

49 Liu J, Li J L, Huang Y S, et al. Study on unloaded rock mass constitution. Earth Environ, 2005, 33: 112-116

50 Xiao Y, Liu H L, Liang R Y. Modified Cam-Clay model incorporating unified nonlinear strength criterion. Sci China Tech Sci, 2011, 54: $805-810$ 
51 Liu H L, Xiao Y, Liu J Y. A new elliptic-parabolic yield surface model revised by an adaptive criterion for granular soils. Sci China Tech Sci, 2010, 53: 2152-2159

52 Wang K P, Li J L, Zhu Z L. Another expression of the principal tension strain failure criterion for concrete. J Gezhouba Inst HydroElectr Eng, 1995, 17: 28-32

53 Xie H P, Li L Y, Ju Y, et al. Energy analysis for damage and catastrophic failure of rocks. Sci China Tech Sci, 2011, 54(suppl 1): 199-209

54 Mazars J, Pijaudier-cabort G. Continuum damage theory-application to concerte. J Eng Mech ASCE, 1987, 115: 345-365

55 Zhou H W, Mishnaevsky Jr L, Brøndsted P, et al. SEM in situ laboratory investigations on damage growth in GFRP composite under three-point bending tests. Chin Sci Bull, 2010, 55: 1199-1208

56 Gunn R M. Non-linear design and safety analysis of arch dams using damage mechanics. Int J Hydropower Dams, 2001, 8: 22-31

57 Duan S H, Ren Q W, Chen J P, et al. Study on the performance of arch dam influenced by relaxation of the foundations following excavation. Sci China Tech Sci, 2011, 54: 1177-1182

58 Du R Q, Zhang Q, Chen S H, et al. Safety evaluation of Dagangshan arch dam resisting strong earthquakes with a rate-dependency anisotropic damage model. Sci China Tech Sci, 2011, 54: 531-540

59 Zhang G X, Liu Y, Zheng C Y, et al. Simulation of influence of multidefects on long-term working performance of high arch dam. Sci China Tech Sci, 2011, 54(suppl 1): 1-8

60 Wang W M, Ding J X, Wang G J, et al. Stability analysis of the temperature cracks in Xiaowan arch dam. Sci China Tech Sci, 2011, 54: 547-555

61 Li S J, Feng X T, Li Z H, et al. In situ experiments on width and evolution characteristics of excavation damaged zone in deeply buried tunnels. Sci China Tech Sci, 2011, 54(suppl 1): 167-174

62 Zhou H, Zhang K, Feng X T. A coupled elasto-plastic-damage mechanical model for marble. Sci China Tech Sci, 2011, 54(suppl 1): 228-234

63 Lu Y F, Wu X X, Shao J F. Anisotropic damage coupled modeling of saturated porous rock. Sci China Tech Sci, 2010, 53: 2681-2690

64 Deng A M, Xu X Q, Wang X D, et al. Thermal cracks in concrete arch dams and their propagation stability. J Hehai Univ, 2002, 30: 91-94

65 Wriggers P, Moftah S O. Mesoscale models for concrete: Homogenisation and damage behaviour. Finite Elem Anal Des, 2006, 42: 623-636

66 Cusatis G, Cedolin L. Two-scale study of concrete fracturing behavior. Eng Fract Mech, 2007, 74: 3-17

67 Cusatis G, Bazant Z P, Cedolin L. Confinement-shear lattice model for concrete damage in tension and compression: I. Theory. J Eng Mech-ASCE, 2003, 129: 1439-1448

68 Grassl P, Bazant Z P. Random lattice-particle simulation of statistical size effect in quasi-brittle structures failing at crack initiation. J Eng Mech-ASCE, 2009, 135: 85-92

69 Leite J P B, Slowik V, Mihashi H. Computer simulation of fracture processes of concrete using mesolevel models of lattice structures. Cem Concr Res, 2004, 34: 1025-1033

70 Ying Z Q, Du C B, Sun L G. A mesoscopic numerical simulation method for fracture of concrete. Key Eng Mater, 2007, 332: 213-216

71 Nazari A, Riahi S. Computer-aided design of the effects of $\mathrm{CrO}$ nanoparticles on split tensile strength and water permeability of high strength concrete. Sci China Tech Sci, 2011, 54: 663-675

72 Zhu X Y, Chen W Q, Huang Z Y, et al. Fast multipole boundary element analysis of 2D viscoelastic composites with imperfect interfaces. Sci China Tech Sci, 2010, 53: 2160-2171

73 Chen W Q, Zhu X Y, Huang Z Y. Modeling of multi-inclusion composites with interfacial imperfections: Micromechanical and numerical simulations. Sci China Tech Sci, 2010, 53: 720-730

74 Xu S L, Yu W T, Song S D. Numerical simulation and experimental study on electrothermal properties of carbon/glass fiber hybrid textile reinforced concrete. Sci China Tech Sci, 2011, 54: 2421-2428

75 Mungule M, Raghuprasad B K. Meso-scale studies in fracture of concrete: A numerical simulation. Comput Struct, 2012, 89: 912-920

76 Grassl P, Gregoire D, Solano L R. Meso-scale modelling of the size effect on the fracture process zone of concrete. Int J Solids Struct, 2012, 49: 1818-1827

77 Wu K. Nonlocal multiscale method and its application in the meso- level analysis of concrete gravity dam. Ph.D. Thesis. Beijing: Tsinghua University, 2010

$78 \mathrm{Xu}$ L, Ren Q W. Numerical simulation on the shear strength of fractal rock joints with different filling percentage. Coal Geol Explor, 2007, 35: 52-55

79 Xu L, Ren Q W, Wang W, et al. Nonlinear elasto-plastic softening constitutive model for rock interfaces and joints. Chin J Appl Mech, 2008, 25: 462-465

80 Dui G S, Wang Z D, Ren Q W. Explicit formulations of tangent stiffness tensors for isotropic materials. Int J Numer Meth Eng, 2007, 69: 665-675

81 Zhu F W, Dui G S, Ren Q W. A continuum model of jointed rock masses based on micromechanics and its integration algorithm. Sci China Tech Sci, 2011, 54: 581-590

82 Wang Z Q, Dui G S. Two-point constitutive equations and integration algorithms for isotropic-hardening rate-independent elastoplastic materials in large deformation. Int J Numer Meth Eng, 2008, 75: 14351456

83 Dui G S. Some basis-free formulae for the time rate and conjugate stress of logarithmic strain tensor. J Elast, 2006, 83: 113-151

84 Chai J R, Xu W S. Coupling analysis of unsteady seepage and stress fields in discrete fractures network of rock mass in dam foundation. Sci China Tech Sci, 2011, 54(suppl 1): 133-139

85 Hu R, Chen Y F, Zhou C B. Modeling of coupled deformation, water flow and gas transport in soil slopes subjected to rain infiltration. Sci China Tech Sci, 2011, 54: 2561-2575

86 Yang Q X, Xu P, Zheng S F. Experimental study of CT test on the failure of acrylate spray-applied waterproof layer in the groundwater environment. Sci China Tech Sci, 2010, 53: 512-518

87 Huang Z Q, Yao J, Li Y J. Permeability analysis of fractured vuggy porous media based on homogenization theory. Sci China Tech Sci, 2010, 53: 839-847

88 Zhan N Y, Yang M, Xu P W. A two-dimensional study on natural convection and heat transfer in the enclosure with heat transfer and radiation coupled in natural convection. Sci China Tech Sci, 2010, 53: 991-999

89 Zhang Y J, Zhang W Q. 3D thermo-hydro-mechanical-migratory coupling model and FEM analyses for dual-porosity medium. Sci China Tech Sci, 2010, 53: 2172-2182

90 Cai G Q, Zhao C G, Liu Y. A nonlinear multi-field coupled model for soils. Sci China Tech Sci, 2011, 54: 1300-1314

91 Zhu B J, Cheng H H, Qiao Y C, et al. Porosity and permeability evolution and evaluation in anisotropic porosity multiscale-multiphasemulticomponent structure. Chin Sci Bull, 2012, 57: 320-327

92 Liu H W, Wang Z K, Zhang Y L. Coupled modeling and analysis of radiometer effect and residual gas damping on proof mass in purely gravitational orbit. Sci China Tech Sci, 2011, 54: 894-902

93 Chen S H, Wang W M, Xu M Y, et al. Finite element analysis of crack propagation in high arch dam heel of Xiaowan project. $\mathrm{J}$ Hydraul Eng, 2003, 34: 66-71

$94 \mathrm{Ju}$ Y, Wang H J, Yang Y M, et al. Numerical simulation of mechanisms of deformation, failure and energy dissipation in porous rock media subjected to wave stresses. Sci China Tech Sci, 2010, 53: 1098-1113

95 Yan X S, Ye H F, Zhao Y Q, et al. 3D time-domain regular grid infinite element in elastic foundation. Sci China Tech Sci, 2010, 53: 1413-1423

96 Zhang Z H, Yang Z J, Liu G H, et al. An adaptive scaled boundary finite element method by subdividing subdomains for elastodynamic problems. Sci China Tech Sci, 2011, 54(suppl 1): 101-110

$97 \mathrm{Tu} \mathrm{C}, \mathrm{Hu}$ X, Yan Z A, et al. First imaging observation of the gravity waves in the meso-pause region in China. Chin Sci Bull, 2010, 55: 539-543

98 Tian L F, Yi S H, Zhao Y X, et al. Aero-optical wavefront measurement technique based on BOS and its applications. Chin Sci Bull, 2011, 56: 2320-2326

99 Liu G H, Guo W, Li H N. An effective and practical method for solving an unnegligible problem inherent in the current calculation model for multi-support seismic analysis of structures. Sci China Tech Sci, 2010, 53: 1774-1784 
100 Yang Q, Leng K D, Liu Y R. A finite element approach for seismic design of arch dam-abutment structures. Sci China Tech Sci, 2011, 54: 516-521

101 Wang J T, Jin F, Zhang C H. Seismic safety of arch dams with aging effects. Sci China Tech Sci, 2011, 54: 522-530

102 Liu J, Zhao C B, Yun B. Numerical study on explosion-induced fractures of reinforced concrete structure by beam-particle model. Sci China Tech Sci, 2011, 54: 412-419

103 Liu F, Chao J P, Huang G, et al. A semi-analytical model for the propagation of Rossby waves in slowly varying flow. Chin Sci Bull, 2011, 56: 2727-2731

104 Ran Z. Multiscales and cascading in isotropic turbulence. Chin Sci Bull, 2011, 56: 2889-2892

105 Rots J G, Nauta P, Kusters M A, et al. Smeared crack approach and fracture localization in concrete. Heron, 1985, 30: 1-50

106 Liu Y R, Chang Q, Yang Q, et al. Fracture analysis of rock mass based on 3-D nonlinear finite element method. Sci China Tech Sci, 2011, 54: 556-564

107 Fu S J, He T, Wang G J, et al. Evaluation of cracking potential for concrete arch dam based on simulation feedback analysis. Sci China Tech Sci, 2011, 54: 565-572

108 Bazant Z P, Cedolin L. Finite element modeling of crack band propagation. J Struct Eng ASCE, 1983, 109: 69-82

109 Bazant Z P. Concrete fracture models: testing and practice. Eng Fract Mech, 2002, 69: 165-205

110 Jiang Y Z, Ren Q W, Xu W, et al. Definition of the general initial water penetration fracture criterion for concrete and its engineering application. Sci China Tech Sci, 2011, 54: 1575-1580

111 Huang D, Zhang Q, Qiao P Z. Damage and progressive failure of concrete structures using non-local peridynamic modeling. Sci China Tech Sci, 2011, 54: 591-596

112 Zhang G X, Yang B, Shen X P, et al. Nonlinear analysis for cracks in gentle volume expansive concrete arch dam. J Hydroelectr Eng, 2004, 23: 51-55

113 Feng B L, Xu D Y, Zhou X G, et al. Fracture mechanics analysis method of crack in arch dam under temperature loading. J Hefei Univ Tech, 2000, 23: 1003-1008

114 Horii H, Chen S C. Computational fracture analysis of concrete gravity dams by crack-embedded elements-toward an engineering evaluation of seismic safety. Eng Fract Mech, 2003, 70: 1029-1045

115 Kaplan M F. Crack propagation and fracture of concrete. Am Concr Inst, 1961, 58: 591-610

116 Hillerborg A, Modeer M, Petersson P E. Analysis of crack formation and crack growth in concrete by means of fracture mechanics and finite elements. Cement Concr Res, 1976, 6: 773-782

117 Shen J, Zhao Y S, Duan K L. Numerical simulation of hydraulic fracture in low permeable coal and rock mass. J China Coal Soc, 1997, 22: 580-585

118 Simoni L, Secchi S. Cohesive fracture mechanics for a multi-phase porous medium. Eng Comput, 2003, 20: 675-698

119 Moes N, Dolbow J, Belytschko T. A finite element method for crack growth without remeshing. Int J Numer Meth Eng, 1999, 46: 131-150

120 Moes N, Belytschko T. Extended finite element method for cohesive crack growth. Eng Fract Mech, 2002, 69: 831-833

121 Babuska I, Melenk J M. The partition of unity method. Int J Numer Meth Eng, 1996, 40: 727-758

122 Ren Q W, Dong Y W, Yu T T. Numerical modeling of concrete hydraulic fracturing with extended finite element method. Sci China Tech Sci, 2009, 52: 559-565

123 Yu T T, Ren Q W. Modeling crack in viscoelastic media using the extended finite element method. Sci China Tech Sci, 2011, 54: 1599-1606

124 Zheng D J, Huo Z Y, Li B. Arch-dam crack deformation monitoring hybrid model based on XFEM. Sci China Tech Sci, 2011, 54: 2611-2617
125 Dong Y W, Ren Q W. An extended finite element method for modeling hydraulic fracturing in gravity dam. J Hydraul Eng, 2011, 42: 1361-1367

126 Xia X Z, Zhang Q, Wang H, et al. The numerical simulation of interface crack propagation without re-meshing. Sci China Tech Sci, 2011, 54: 1923-1929

127 Chul-Hee J O, Sung-Woo I M, Won-Chul C H O, et al. Fatigue crack in large-scale tubular joints for offshore structures. Sci China Tech Sci, 2011, 54: 705-714

128 Tian B, Xia S Y. Finite element analysis of high arch dam cracking at dam heel. Yangze River, 1997, 28: 32-34

129 Ren Q W. A preliminary study of allowable cracking in concrete dam. In: The 1st National Conference on the Safety Issues of High Dam, 2010

130 Evans R H, Marathe M S. Microcracking and tress-strain curves for concrete in tension. Mater Struct, 1968 1: 61-64

131 Gerard B, Breysse D, Ammouche A. Cracking and permeability of concrete under tension. Mater Struct, 1996, 29: 141-151

132 Zhang X F, Xu S L. Correlation between the tension softening relation and crack extension resistance GR in concrete. J Tsinghua Univ, 2008, 48: 316-320

133 Xu S L, Wang J M. Crack propagation in a concrete dam under water pressure and determination of the double $\mathrm{K}$ fracture parameters. Chin Civil Eng J, 2009, 42: 119-125

134 Bao T F, Peng Y, Cong P J, et al. Analysis of crack propagation in concrete structures with structural information entropy. Sci China Tech Sci, 2010, 53: 1943-1948

135 Lai J Z, Sun W. Dynamic damage and stress-strain relations of ultrahigh performance cementitious composites subjected to repeated impact. Sci China Tech Sci, 2010, 53: 1520-1525

136 Wang S S, Ren Q W. Dynamic response of gravity dam model with crack and damage detection. Sci China Tech Sci, 2011, 54: 541-546

137 Gao J, Ji J R, Huang H Y. Statistical models for arch dam shape design. J Hohai Univ, 1997, 25: 58-64

138 Liu X J, Li Z D, Chen X. A new solution for topology optimization problems with multiple loads: The guide-weight method. Sci China Tech Sci, 2011, 54: 1505-1514

139 Sun L S, Wang D X, Sun W J. Shape optimization of arch dam subject to crack depth constraint. J Hydraul Eng, 1998, 29: 18-22

140 Zhong G L, Ren B Y, Tong D W. Study on multi-scheme analysis and evaluation method for concrete sequence placement of high arch dam. Sci China Tech Sci, 2011, 54(suppl 1): 47-53

141 Zhong D H, Zhao C S, Ren BY. Research on analysis method for temperature control information of high arch dam construction. Sci China Tech Sci, 2011, 54(suppl 1): 40-46

142 Zhong D H, Ren B Y, Li M C. Theory on real-time control of construction quality and progress and its application to high arc dam. Sci China Tech Sci, 2010, 53: 2611-2618

143 Fu S J, He T, Wang G J, et al. Evaluation of cracking potential for concrete arch dam based on simulation feedback analysis. Sci China Tech Sci, 2011, 54: 565-572

144 Bao T F, Wang J L, Yao Y. A fiber optic sensor for detecting and monitoring cracks in concrete structures. Sci China Tech Sci, 2010, 53: 3045-3050

145 Bao T F, Qin D, Zhou X W, et al. Abnormality monitoring model of cracks in concrete dams. Sci China Tech Sci, 2011, 54: 1914-1922

$146 \mathrm{Gu} \mathrm{C} \mathrm{S,} \mathrm{Li} \mathrm{Z} \mathrm{C,} \mathrm{Xu} \mathrm{B.} \mathrm{Abnormality} \mathrm{diagnosis} \mathrm{of} \mathrm{cracks} \mathrm{in} \mathrm{the} \mathrm{con-}$ crete dam based on dynamical structure mutation. Sci China Tech Sci, 2011, 54: 1930-1939

147 Liu H W, Chen J, Sun M, et al. Theoretical analysis and experiment of micromechanics and mechanics-optics coupling of distributed opticfiber crack sensing. Sci China Tech Sci, 2011, 54(suppl 1): 185-191

148 Lei P, Chang X L, Xiao F. Study on early warning index of spatial deformation for high concrete dam. Sci China Tech Sci, 2011, 54: $1607-1614$

Open Access This article is distributed under the terms of the Creative Commons Attribution License which permits any use, distribution, and reproduction in any medium, provided the original author(s) and source are credited. 